\title{
Dyeing of Silk with Anthocyanins Dyes Extract from Liriope platyphylla Fruits
}

\author{
Huayin Wang, ${ }^{1}$ Ping Li, ${ }^{2}$ and Wenlong Zhou' \\ ${ }^{1}$ Key Laboratory of Advanced Textile Materials and Manufacturing Technology (Ministry of Education), \\ Zhejiang Sci-Tech University, Hangzhou, Zhejiang 310018, China \\ ${ }^{2}$ Yancheng Institute of Industry Technology, Yancheng, Jiangsu 224005, China
}

Correspondence should be addressed to Ping Li; yiitliping@163.com

Received 14 May 2014; Accepted 28 July 2014; Published 20 August 2014

Academic Editor: Joanne Yip

Copyright (C) 2014 Huayin Wang et al. This is an open access article distributed under the Creative Commons Attribution License, which permits unrestricted use, distribution, and reproduction in any medium, provided the original work is properly cited.

\begin{abstract}
A new source of natural anthocyanins dyes, from Liriope platyphylla fruit, is proposed. This paper analyzes the dye extracts, the primary color components of the extracts, the color features of the extracts under different $\mathrm{pH}$ conditions, and their application in silk dyeing. The research shows that, nine anthocyanins are found in L. platyphylla fruits by analyzing the results of the HPLC/DAD, MS, and MS/MS spectra. The five major anthocyanins related to delphinidin, petunidin, and malvidin derivatives take up $91.72 \%$ of total anthocyanin contents. The color of the solution is red under acidic condition $(\mathrm{pH}<3.0)$ and stays in yellow under alkaline condition with $\mathrm{pH}$ values above 7.0. The dye extracts applied to silk fabric with mordant free dyeing show different color under different $\mathrm{pH}$ conditions, changing between purple, blue, green, and yellow. However, the dyed colors is light and the dyeing rate is low. Metal mordant such as Sn in chelation enhances the dye depth and improves the fastness of the dyed silk fabrics, especially in silk fabrics dyed by premordanting and metamordanting.
\end{abstract}

\section{Introduction}

Natural dyes are generally environment friendly and have many advantages over synthetic dyes. In recent years, the applications of natural dyes are researched due to their biodegradability and higher compatibility with the environment [1-3]. Anthocyanins, with their common structure shown in Figure 1, are flavonoids commonly found in flower petals, fruits, and leaves and produce orange, red, violet, and blue colours [4,5]. Earlier studies show that anthocyanins are especially abundant in bilberry, strawberry, raspberry, grape skin, blackberry, and so on [6-10]. Interests in these water-soluble pigments have been increased substantially during the last decade because of the increasing evidence demonstrating potential therapeutic effects. Researches also show that anthocyanins have strong oxidation resistance, inhibit the growth of cancerous cells, inhibit inflammation, and have antiobesity effects. The therapeutic properties of anthocyanins have been reviewed and proved [11-14]. Despite the great application potentials that anthocyanins represent for food, pharmaceutical, and cosmetic industries, their application in textile is limited as the pigments lack affinity for the fiber and cannot be sustained during washing and therefore requires further investigation.

In general, anthocyanins show colour variation caused by $\mathrm{pH}$ or metal chelation changes. As natural dye used in textile, it is important to study the color coordinates of anthocyanin dye extracts and the dyed fabrics influenced by the $\mathrm{pH}$ values of dyeing bath, the metal mordant, and the mordanting processes, which would help to understand the basic color effects of the dyed fabrics using anthocyanin extracts as natural dyes.

L. platyphylla is an evergreen perennial, widely distributed in China, India, Japan, and Korea. Its dried tubers have been commonly used as traditional herbal medicine to cure acute and chronic inflammation and cardiovascular diseases including thrombotic diseases $[15,16]$. Various phytochemical and biochemical investigations on tubers of $L$. platyphylla have been reported [17-19]. However, up to now, few reports can be found on analysis and applications of the fruits of L. platyphylla. In this work, the analysis of the anthocyanin components of the L. platyphylla fruit extracts was 


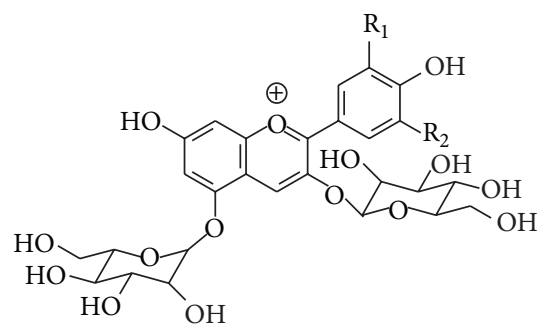

\begin{tabular}{cccc}
\hline $\mathrm{R}_{1}$ & $\mathrm{R}_{2}$ & Anthocyanin & Aglycon \\
\hline $\mathrm{H}$ & $\mathrm{H}$ & Pelargonin & Pelargonidin \\
$\mathrm{OH}$ & $\mathrm{H}$ & Cyanin & Cyanidin \\
$\mathrm{OCH}_{3}$ & $\mathrm{H}$ & Peonin & Peonidin \\
$\mathrm{OH}$ & $\mathrm{OH}$ & Delphin & Delphinidin \\
$\mathrm{OCH}_{3}$ & $\mathrm{H}$ & Petunin & Petunidin \\
$\mathrm{OCH}_{3}$ & $\mathrm{OCH}_{3}$ & Malvin & Malvidin \\
\hline
\end{tabular}

FIGURE 1: Structure of common anthocyanins.

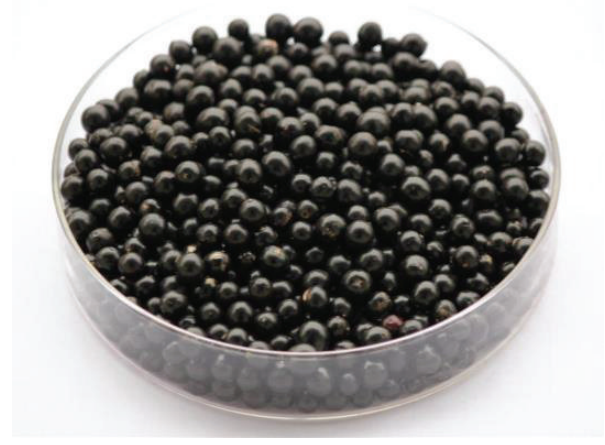

FIGURE 2: Fruits used for extraction.

performed with HPLC/DAD, MS, and MS/MS spectra. The color coordinates of the extracts and silk fabrics dyed by the extracts were analyzed with CIE1964-XYZ and CIE1976LAB of the Commission Internationale de L'Éclairage.

\section{Experiments}

2.1. Chemicals. The methanol, $\mathrm{SnCl}_{2}$, and hydrochloric acid were analytical-grade reagents obtained from Tianjin Kemiou Chemical Reagent Co., Ltd. (China). Trifluoroacetic acid (TFA) was analytical-grade reagent obtained from Aladdin Chemistry Co., Ltd. (China).

2.2. Plant Material. Fruits of L. platyphylla were harvested in Zhejiang Sci-Tech University, Hangzhou, Zhejiang, China, in January 2013 and the samples (Figure 2) were packed immediately and stored in a freezer at $-20^{\circ} \mathrm{C}$ until processed.

One criterion of the fruit is its moisture content, which is evaluated first for the fresh fruits. Moisture content is the percentage of water contained in a material. $100 \mathrm{~g}$ of the fresh fruits was taken and kept in an oven at $100^{\circ} \mathrm{C}$ for $24 \mathrm{~h}$ and weighted afterward. Triplicate assays were applied. The moisture content (\%) of the fresh fruits is $50.2 \pm 8.6 \%$.

2.3. Extraction of Anthocyanin Dyes. The fruits were crushed with a mortar and weighed for preparation. Three typical methods are used in this paper, which are mainly differentiated by the solvents used. All the three methods extracted anthocyanins by putting the fruits into a curtain solvent, stirring them for $10 \mathrm{~min}$, and keeping them $24 \mathrm{~h}$ at room

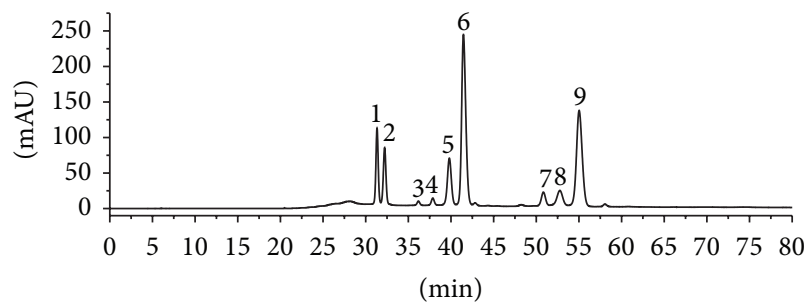

FIGURE 3: HPLC separation of anthocyanins in the fruits of $L$. platyphylla.

temperature in darkness without stirring [30,31]. The mixture was then filtered through a Buchner funnel under vacuum. The solid residue was washed with the same solvent until a clear solution was obtained. The combined filtrates were dried using a rotary evaporator at $55^{\circ} \mathrm{C}$ or $60^{\circ} \mathrm{C}$, which was chosen individually for each solvent for the best extraction results. The concentrate was dissolved in distill water and the solution obtained was used for dyeing. The first method uses methanol containing $0.1 \%(\mathrm{~V} / \mathrm{V})$ of concentrated hydrochloric acid with $55^{\circ} \mathrm{C}$ for drying and the second method uses solvent $\mathrm{CH}_{3} \mathrm{OH} / \mathrm{TFA} / \mathrm{H}_{2} \mathrm{O} 49.5 / 0.5 / 50 \mathrm{v} / \mathrm{v} / \mathrm{v}$ with $60^{\circ} \mathrm{C}$ for drying, while the third method uses methanol containing 5.0\% $(\mathrm{W} / \mathrm{V})$ of concentrated citric acid with $55^{\circ} \mathrm{C}$ for drying.

2.4. Total Anthocyanins Content Measurement. Total anthocyanins content (TAC) was normally determined using $\mathrm{pH}$ differential method and expressed as cyanidin-3-glucoside (Cy-3-glc) equivalents, according to the following formula $[32,33]$ :

$$
c[\mathrm{mg} / \mathrm{L}]=\frac{A \times M_{w} \times \mathrm{DF} \times 1000}{\varepsilon_{M} \times d},
$$

where $A$ is the absorbance value in visible region, equaling $\left(A_{\lambda \max }-A_{700}\right)_{\mathrm{pH} 1.0}-\left(A_{\lambda \max }-A_{700}\right)_{\mathrm{pH} 4.5}$, which corresponds to sodium acetate-acetic acid buffer solution when $\mathrm{pH}=4.5$ and potassium chloride-hydrochloric acid buffer solution when $\mathrm{pH}=1.0$ to dilute the anthocyanin extracts; $M_{w}$ is the molecular weight $(\mathrm{g} / \mathrm{mol})$ of Cy-3-glc $(449.2 \mathrm{~g} / \mathrm{mol}$ in the analysis); DF is the dilution factor; $\varepsilon_{M}$ is the molar extinction coefficient (26,900 for Cy-3-glc); and $d$ is the path length of the cuvette $(1 \mathrm{~cm}$ in the analysis). The experiments were performed in triplicate assays. 


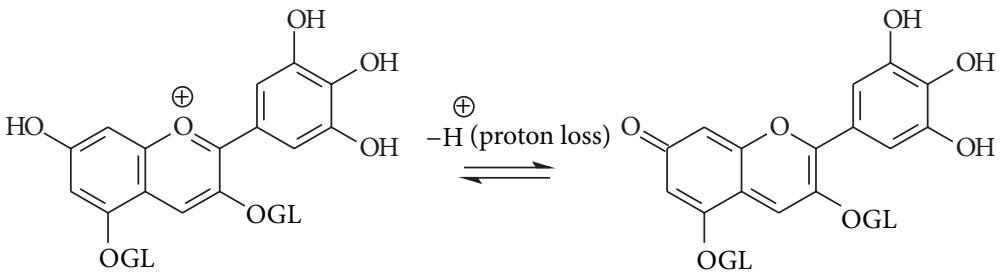

Flavylium cation (red)<smiles></smiles>

Quinoidal base (blue)<smiles>C#CCOc1cc(O)cc2c1C=C(Oc1ccccc1)C(O)(c1cc(O)c(O)c(O)c1)O2</smiles>

FIGURE 4: Structure change of anthocyanin with $\mathrm{pH}$ in aqueous solution.

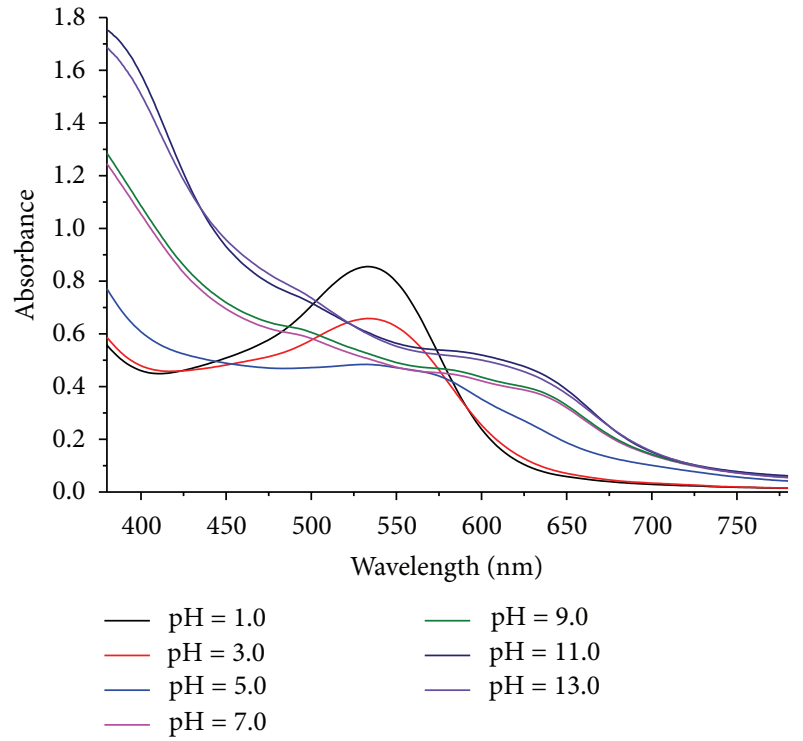

FIGURE 5: Visible spectra of L. platyphylla fruit extracts at several $\mathrm{pH}$ values.

TABLE 1: Total anthocyanin contents by different acids (mg/100 g fresh weight; mean \pm SD of triplicate assays).

\begin{tabular}{lc}
\hline Extracting acid & TAC \\
\hline $0.1 \% \mathrm{HCl}$ & $474.45 \pm 25.67$ \\
$5 \%$ citric acid & $615.84 \pm 34.21$ \\
$0.5 \%$ TFA & $535.37 \pm 28.75$ \\
\hline
\end{tabular}

2.5. HPLC/DAD Analysis. HPLC/DAD experiments were performed using the HPLC machine (1260 Infinity, Agilent Technologies, CA, USA). For analysis, the separations of anthocyanins were carried out on Agilent Zorbax SB-C18 column $(4.6 \times 250 \mathrm{~mm}, 5 \mu \mathrm{m})$ (Agilent Technologies, CA, USA)

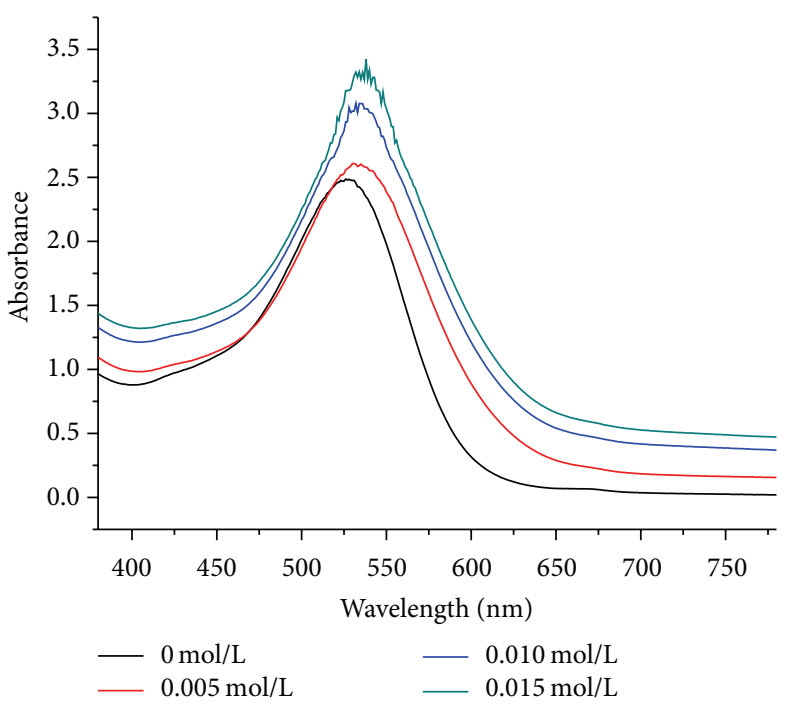

FIGURE 6: Visible spectra of Sn chelated anthocyanins extracts in buffer solutions at $\mathrm{pH}$ 1.0.

equipped with a C18 guard column (Agilent Technologies, CA, USA). The column oven temperatures were set to $35^{\circ} \mathrm{C}$. The mobile phase consisted of $5 \%$ formic acid (solvent $\mathrm{A}$ ) and $100 \% \mathrm{CH}_{3} \mathrm{CN}$ (solvent B). For the separation of anthocyanin extracts on SB-C18 column $(4.6 \times 250 \mathrm{~mm}, 5 \mu \mathrm{m})$, the elution conditions were set as follows: isocratic elution $0 \% \mathrm{~B}, 0$ $10 \mathrm{~min}$; linear gradient from $0 \% \mathrm{~B}$ to $10 \% \mathrm{~B}, 10-20 \mathrm{~min} ; 14 \% \mathrm{~B}$, 20-60 min; $100 \% \mathrm{~B}, 60-80 \mathrm{~min}$; flow rate $0.5 \mathrm{~mL} \mathrm{~min}^{-1}$; and injection volumes $10 \mu \mathrm{L}$. The detected wavelength was $520 \mathrm{~nm}$ and all spectra peaks from $250 \mathrm{~nm}$ to $640 \mathrm{~nm}$ were recorded.

2.6. HPLC/MS and HPLC/MS/MS Analysis. HPLC/MS and HPLC/MS/MS experiments were performed using the same HPLC machine (Agilent Technologies) equipped with a mass 
TABLE 2: Identification of anthocyanins in L. platyphylla fruit extracts.

\begin{tabular}{|c|c|c|c|c|c|c|c|c|c|}
\hline Peak & $\mathrm{RT}(\min )$ & MS & $\mathrm{MS}^{2}$ & $\lambda_{\text {vis,max }}$ & $\lambda_{\text {acyl,max }}$ & $\begin{array}{l}\text { UV-Vis data } \\
A_{440} / A_{\text {vis,max }}\end{array}$ & $A_{\text {acyl,max }} / A_{\text {vis,max }}$ & Tentative identification & References \\
\hline 1 & 31.330 & 465 & 303 & 524 & 346 & 28.74 & 9.51 & Dp 3-glu & {$[20-22]$} \\
\hline 2 & 32.217 & 611 & $465 / 303$ & 525 & 347 & 28.18 & 9.51 & Dp 3-rut & {$[23]$} \\
\hline 3 & 35.882 & 479 & 317 & 515 & 332 & 32.47 & 6.84 & Pt 3-gal & {$[21,24]$} \\
\hline 4 & 37.867 & 595 & $449 / 287$ & 517 & 325 & 31.13 & 18.13 & Cy 3-rut & {$[21,23,25-27]$} \\
\hline 5 & 39.807 & 479 & 317 & 525 & 345 & 27.99 & 11.19 & Pt 3-glu & {$[21,22,26,28]$} \\
\hline 6 & 41.460 & 625 & $479 / 317$ & 527 & 347 & 27.38 & 9.97 & Pt 3-rut & {$[23]$} \\
\hline 7 & 50.835 & 609 & $463 / 301$ & 518 & 331 & 31.97 & 8.77 & Pn 3-rut & {$[23,24,29]$} \\
\hline 8 & 52.762 & 493 & 331 & 527 & 348 & 27.96 & 11.48 & Mv 3-glu & {$[20-22]$} \\
\hline 9 & 55.024 & 639 & $493 / 331$ & 528 & 348 & 26.86 & 10.57 & Mv 3-rut & {$[23]$} \\
\hline
\end{tabular}

RT: retention time; Dp: delphinidin; Cy: cyanidin; Pt: petunidin; Pn: peonidin; Mv: malvidin; glu: glucoside; rut: rutinoside; gal: galactoside.

spectrometer (LCQ FLEET, Thermo Fisher Scientific, PA, USA) and electrospray ionization (ESI). The HPLC column and HPLC conditions for the mobile gradient were the same as those in HPLC/DAD experiments. The MS analytical parameters were as follows: polarity, positive; ion source, turbo spray (ESI); capillary temperature, $350^{\circ} \mathrm{C}$; capillary voltage, $60 \mathrm{~V}$; spray voltage, $4.5 \mathrm{KV}$; and full-scan range, from $\mathrm{m} / z$ 400-1200. $\mathrm{MS}^{2}$ scan of the most abundant ion uses relative collision energy of $20 \%$.

2.7. Mordanting. The weighed silk fabrics were treated with tin metal salts for premordanting, metamordanting, and postmordanting. The amount of mordant used was 5\% (o.w.f.). The fabrics were mordanted at liquor ratio of $50: 1$. In premordanting, fabrics were immersed in the mordant solution at $60^{\circ} \mathrm{C}$ for $30 \mathrm{~min}$. In metamordanting, fabrics were immersed in a dyeing bath containing both mordant and extracted dyes for $120 \mathrm{~min}$. In postmordanting, fabrics were immersed in a dyeing bath containing only extracted dyes for $120 \mathrm{~min}$ and only mordant at $60^{\circ} \mathrm{C}$ for $30 \mathrm{~min}$, separately. Due to the light sensitivity of the mordants, fabrics after mordanting should be dyed immediately.

2.8. Dyeing. The weighted silk fabric was dyed at a liquor ratio of $50: 1.20 \mathrm{~g}$ of dye concentrates was dissolved in $1000 \mathrm{~mL}$ deionized water for a piece of fabric weighing $20 \mathrm{~g}$. The fabric was kept in dye bath for $120 \mathrm{~min}$ at $60^{\circ} \mathrm{C}$. The $\mathrm{pH}$ value of the dyeing solution was adjusted with dilute solutions of hydrochloric acid or sodium hydroxide. The dyed fabric was rinsed with cold water and finally dried at room temperature in shade.

2.9. Color Analysis. Colorimetric methods are very useful in characterizing the color properties of pigments. Tristimulus colorimetry has been widely applied. An absorbance spectrum $(\Delta \lambda=1 \mathrm{~nm})$ of anthocyanin dye solutions was recorded with a UV-VIS double-beam Spectrophotometers TU-1950 (Beijing Purkinje General Instrument Co., Ltd., Beijing, China). D65 standard illuminant and $10^{\circ}$ standard observer
TABle 3: Color coordinates of the L. platyphylla fruit extract at several $\mathrm{pH}$ values.

\begin{tabular}{lccccc}
\hline $\mathrm{pH}$ & $L^{*}$ & $a^{*}$ & $b^{*}$ & $C^{*}$ & $h$ \\
\hline 1.0 & 62.21 & 45.84 & 0.80 & 45.84 & 1.00 \\
3.0 & 65.82 & 33.99 & 3.69 & 34.19 & 6.20 \\
5.0 & 67.56 & 12.06 & 7.09 & 13.99 & 30.47 \\
7.0 & 64.10 & 4.29 & 21.13 & 21.56 & 78.53 \\
9.0 & 63.04 & 4.74 & 21.47 & 21.99 & 77.54 \\
11.0 & 58.10 & 3.49 & 29.67 & 29.87 & 83.29 \\
13.0 & 58.59 & 4.79 & 32.04 & 32.39 & 81.50 \\
\hline
\end{tabular}

were considered in the calculation. Reference blank measurements were made with the cuvette filled with distilled water. The whole visible spectrum $(380-780 \mathrm{~nm})$ was recorded. The CIELAB parameters $\left(L^{*}, a^{*}, b^{*}, C^{*}\right.$, and $\left.h\right)$ were determined following the CIE1964-XYZ and CIE1976LAB of the Commission Internationale de L'Éclairage.

Color values of dyed fabrics were evaluated by means of color strength $(K / S)$, color differences $\left(\Delta E_{\mathrm{cmc}}\right)$, and other CIELAB values $\left(L^{*}, a^{*}, b^{*}, C^{*}\right.$, and $\left.h\right)$. With $10 \mathrm{~mm}$ sample diameter (geometry $\mathrm{d} / 10^{\circ}$ ), CIELAB values were calculated for illuminant D65 on Datacolor SF600 spectrophotometer with software data match Color Tools 3.1 (Datacolor International, NJ, USA). Five measurements were made on each sample and variations in the percentage reflectance values over range of 400-700 $\mathrm{nm}$ were recorded.

In the uniform space CIELAB, $L^{*}$ corresponds to the brightness $(100=$ white, $0=$ black $), a^{*}$ to the red-green coordinate $($ positive sign $=$ red, negative sign $=$ green $)$, and $b^{*}$ to the yellow-blue coordinate (positive sign = yellow, negative sign $=$ blue $)$. Chroma $\left(C^{*}\right)$ is the quantitative attribute of colourfulness. Hue $(h)$ is the attribute according to which colors are defined as reddish, greenish, and so forth. The total colour difference $\left(\Delta E^{*}\right)$ between two samples is estimated using the following expression:

$$
\Delta E^{*}=\left[\left(\Delta L^{*}\right)^{2}+\left(\Delta a^{*}\right)^{2}+\left(\Delta b^{*}\right)^{2}\right]^{1 / 2},
$$


Silk fabrics obtained by control (without mordant) dyeing

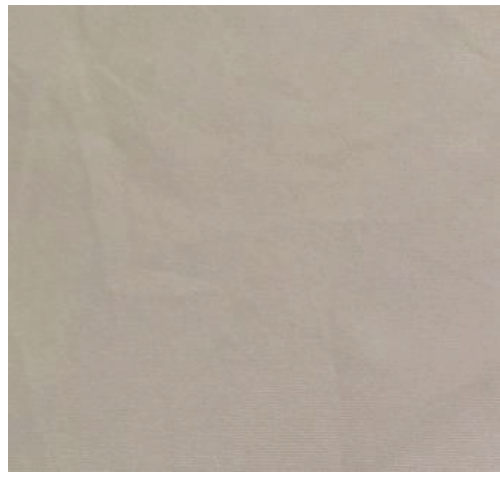

$\mathrm{pH}=1.0$

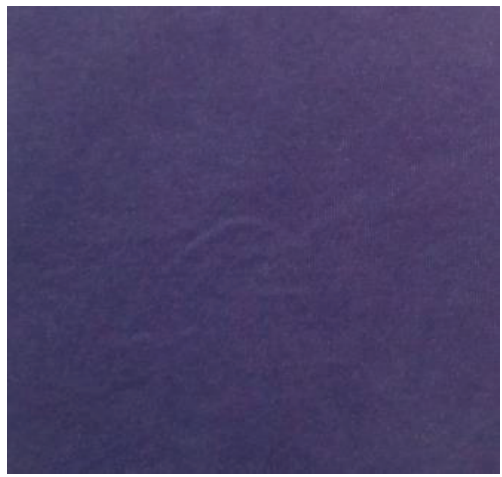

$\mathrm{pH}=1.0$

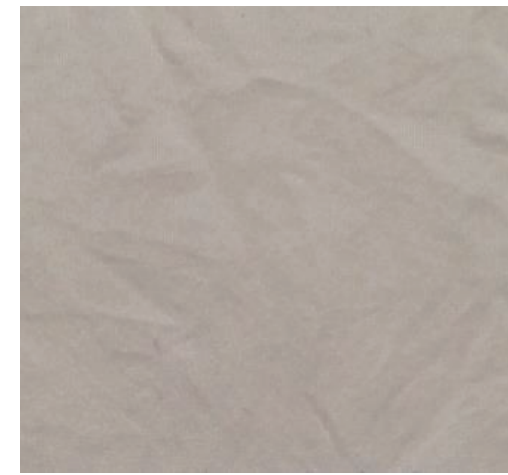

$\mathrm{pH}=7.0$

Silk fabrics obtained by metamordanting dyeing

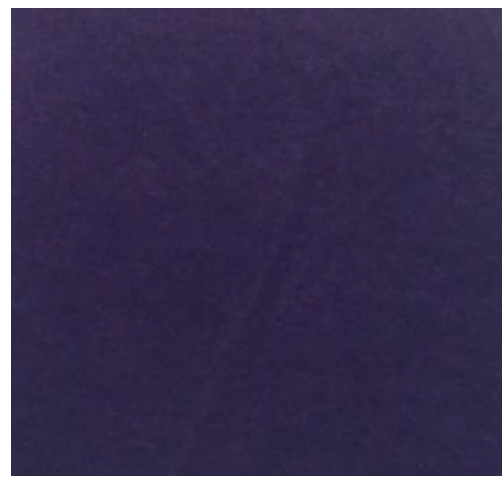

$\mathrm{pH}=7.0$

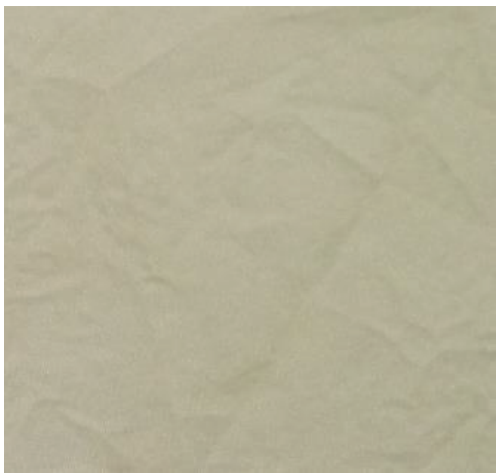

$\mathrm{pH}=13.0$

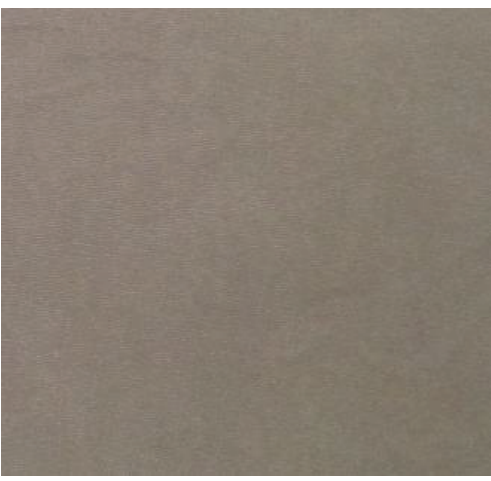

$\mathrm{pH}=13.0$

FIGURE 7: Some colour samples obtained by metamordanting dyeing and control (without mordant) dyeing.

TABLE 4: Color coordinates of the Sn chelated anthocyanins extracts in buffer solutions at $\mathrm{pH}$ 1.0.

\begin{tabular}{lccccccc}
\hline No. & Concentration of $\mathrm{Sn}^{2+}(\mathrm{mol} / \mathrm{L})$ & $\lambda_{\max }(\mathrm{nm})$ & $L^{*}$ & $a^{*}$ & $b^{*}$ & $C^{*}$ & \multicolumn{1}{c}{$h$} \\
\hline 1 & 0 & 526 & 46.90 & 69.19 & 24.84 & 73.52 & 19.75 \\
2 & 0.005 & 531 & 29.72 & 56.47 & -2.30 & 56.52 & 357.66 \\
3 & 0.010 & 532 & 20.74 & 46.53 & -5.05 & 46.80 & 353.80 \\
4 & 0.015 & 534 & 16.91 & 42.43 & -6.83 & 42.97 & 350.85 \\
\hline
\end{tabular}

TABLE 5: Silk dyeing with L. platyphylla fruit extracts at several $\mathrm{pH}$.

\begin{tabular}{ccccccc}
\hline $\mathrm{pH}$ & $L^{*}$ & $a^{*}$ & $b^{*}$ & $C^{*}$ & $h^{*}$ & $\Delta E^{*}$ \\
\hline 1.0 & 58.76 & 16.79 & -7.59 & 18.43 & 335.66 & 40.21 \\
3.0 & 69.26 & 8.88 & 0.41 & 8.89 & 2.65 & 26.14 \\
5.0 & 70.68 & 0.25 & 1.95 & 1.97 & 82.64 & 22.94 \\
7.0 & 71.93 & -0.66 & 7.65 & 7.68 & 94.93 & 22.17 \\
9.0 & 74.66 & -0.17 & 12.73 & 12.73 & 90.76 & 21.29 \\
11.0 & 74.34 & 1.13 & 13.42 & 13.47 & 85.19 & 21.95 \\
13.0 & 80.92 & 2.94 & 18.76 & 18.99 & 81.08 & 20.48 \\
\hline
\end{tabular}

where $\Delta E^{*}$ indicates the total color differences between dyed fabric and undyed original silk fabric. The color indicators of the undyed silk fabric are $L^{*}(93.6), a^{*}(-0.28), b^{*}(3.00)$, $C^{*}(3.01)$, and $h^{*}$ (95.42).
TABLE 6: Silk dyeing with L. platyphylla fruit extracts with tin mordanting at several $\mathrm{pH}$ by premordanting.

\begin{tabular}{ccccccc}
\hline $\mathrm{pH}$ & $L^{*}$ & $a^{*}$ & $b^{*}$ & $C^{*}$ & $h^{*}$ & $\Delta E^{*}$ \\
\hline 1.0 & 45.1 & 15.24 & -15.57 & 21.79 & 314.39 & 54.2 \\
3.0 & 43.76 & 11.92 & -23.95 & 26.75 & 296.47 & 57.96 \\
5.0 & 36.62 & 10.41 & -24.43 & 26.56 & 293.08 & 64.13 \\
7.0 & 42.49 & 5.81 & -19.41 & 20.26 & 286.65 & 56.14 \\
9.0 & 51.61 & 2.01 & -12.77 & 12.93 & 278.93 & 44.91 \\
11.0 & 64.14 & 2.14 & 4.82 & 5.28 & 66.07 & 29.62 \\
13.0 & 72.98 & 0.17 & 9.57 & 9.57 & 88.98 & 21.65 \\
\hline
\end{tabular}

2.10. Fastness Testing of Dyed Fabrics. The dyed silk fabrics were tested according to AATCC standard methods. The specific tests were color fastness to light, AATCC 16-2004; 
TABLE 7: Silk dyeing with $L$. platyphylla fruit extracts with tin mordanting at several $\mathrm{pH}$ by metamordanting.

\begin{tabular}{lcccccc}
\hline $\mathrm{pH}$ & $L^{*}$ & $a^{*}$ & $b^{*}$ & $C^{*}$ & $h^{*}$ & $\Delta E^{*}$ \\
\hline 1.0 & 55.5 & 13.29 & -16.16 & 20.92 & 309.42 & 44.75 \\
3.0 & 55.7 & 8.19 & -15.93 & 17.91 & 297.2 & 43.2 \\
5.0 & 55.52 & 6.34 & -17.93 & 19.05 & 289.44 & 43.97 \\
7.0 & 43.73 & 6.4 & -22.01 & 22.92 & 286.2 & 56.19 \\
9.0 & 52.84 & -0.72 & -18.32 & 18.34 & 267.76 & 46 \\
11.0 & 56.7 & 4.41 & -5.91 & 7.37 & 306.72 & 38.24 \\
13.0 & 63.02 & 2.61 & 2.43 & 3.57 & 42.98 & 30.72 \\
\hline
\end{tabular}

color fastness to crocking, AATCC 8-2007; color fastness to washing, AATCC 61-2009; and color fastness to perspiration, AATCC 15-2009. The colors of the specimens were rated by referencing to the Gray Scale for Color Change. The staining on each undyed original fabric was rated by means of the Gray Scale for Staining.

\section{Results and Discussion}

3.1. Effect of Acids on Total Anthocyanin Content. Anthocyanin from the fruits was extracted using $0.1 \% \mathrm{HCl}, 5 \%$ citric acid, or $0.5 \%$ TFA. The total anthocyanin contents extracted from the fruits using different acids are shown in Table 1 . The results show that the citric acid gives better yield and deeper color, which produce $29.8 \%$ and $15.0 \%$ more anthocyanins than $0.1 \% \mathrm{HCl}$ and $0.5 \% \mathrm{TFA}$, respectively.

3.2. Characterization of Anthocyanins in the Fruit Extracts. Figure 3 shows the HPLC chromatograms of anthocyanin extracts carried on $\mathrm{C} 18$ columns. In Figure 3, nine different anthocyanins from the fruits are identified. Peaks 1, 2, 5, 6, and 9, eluted at $31.330 \mathrm{~min}, 32.220 \mathrm{~min}, 39.807 \mathrm{~min}$, $41.460 \mathrm{~min}$, and $55.024 \mathrm{~min}$, indicate the major anthocyanins and take up $9.32 \%, 8.06 \%, 9.51 \%, 36.54 \%$, and $28.29 \%$ of the total anthocyanin content, respectively. The four others (peaks $3,4,7$, and 8 ) take up total $8.28 \%$, each accounting for $0.5 \%$ to $4 \%$ of the total anthocyanin content.

By combining the results of DAD, MS, and MS/MS spectra, the nine different anthocyanins extracted from the fruit of L. platyphylla are summarized in Table 2. Among the nine different anthocyanins, delphinidin 3-glucoside (Dp 3-glu), delphinidin 3-rutinoside (Dp 3-rut), cyanidin-3-glucoside (Cy-3-glu), petunidin 3-glucoside (Pt 3-glu), petunidin 3rutinoside (Pt 3-rut), malvidin 3-glucoside (Mv 3-glu), and malvidin 3-rutinoside (Mv 3-rut) were confirmed by previous reported NMR spectroscopy data [34].

3.3. Effect of pH Values on Anthocyanin Dye Colors. Anthocyanins show great susceptibility toward $\mathrm{pH}$ variation, being more stable in acidic media at low $\mathrm{pH}$ values than in alkaline solutions at high $\mathrm{pH}$ value. The ionic nature of anthocyanins enables the changes of the molecule structures according to the prevailing $\mathrm{pH}$ values and results in different colors and hues at different $\mathrm{pH}$ values. In acidic aqueous solution, anthocyanins exist in the form of four main equilibrium species
TABLE 8: Silk dyeing with L. platyphylla fruit extracts with tin mordanting at several $\mathrm{pH}$ by postmordanting.

\begin{tabular}{lcccccc}
\hline $\mathrm{pH}$ & $L^{*}$ & $a^{*}$ & $b^{*}$ & $C^{*}$ & $h^{*}$ & $\Delta E^{*}$ \\
\hline 1.0 & 67.46 & 1.07 & -1.93 & 2.21 & 299.03 & 26.63 \\
3.0 & 71.78 & -4.92 & 0.24 & 4.92 & 177.21 & 22.47 \\
5.0 & 72.86 & -5.22 & 0.36 & 5.24 & 176.01 & 21.47 \\
7.0 & 73.49 & -5.3 & 5.91 & 9.01 & 99.46 & 19.85 \\
9.0 & 78.72 & -0.62 & 11.19 & 11.21 & 93.18 & 16.98 \\
11.0 & 76.84 & -0.66 & 11.89 & 11.91 & 93.19 & 18.97 \\
13.0 & 85.93 & -0.86 & 16.75 & 16.77 & 92.95 & 15.76 \\
\hline
\end{tabular}

(Figure 4) [35]: red flavylium cation, blue quinoidal base, colorless carbinol or pseudobase, and yellowish chalcone. Under acidic conditions $(\mathrm{pH}<2.0)$, the anthocyanins exist primarily in the form of red flavylium cation. Increasing the $\mathrm{pH}$ value causes fast loss of the proton and produces quinoidal base forms, blue or violet. At the same time hydration of flavylium cation occurs and the carbinol or pseudobase is generated, which slowly reaches equilibrium and produces the chalcone in faint yellow. The relative amounts of above four forms of anthocyanins at the equilibrium condition vary according to $\mathrm{pH}$ values.

The visible spectra of L. platyphylla fruit extracts at different $\mathrm{pH}$ values are shown in Figure 5. The values of the color indexes are described in Table 3 . Figure 5 shows that, with the increasing of $\mathrm{pH}$ value, the maximum visible absorption peak moves towards the long wavelength. The absorbance decreases first and then increases. Table 3 shows that the color of the solution is red under strong acidic condition $(\mathrm{pH}<3.0)$ and stays in yellow under alkaline condition with $\mathrm{pH}$ value above 7.0.

As seen in Table 3 , the lightness index $L^{*}$ is inversely correlated to the color contents in the solution. When under acidic condition $(\mathrm{pH}<3.0)$, the index $L^{*}$ of the L. platyphylla fruit dye solution is stable, the pigment mainly presents in the form of red anthocyanin molten salt, and the $a^{*}$ is positive and relatively high. When $\mathrm{pH}$ increases to above 3.0, the pigment gradually transforms from colored substances into colorless substances, which are mainly colorless methanol false alkali. When $\mathrm{pH}$ increases to above 5.0, the value of $L^{*}$ starts to increase and the solution color becomes deepened, transforming from red anthocyanin molten salt to blue quinone alkali. With the further increasing of the $\mathrm{pH}$ value, the solution color becomes lighter, since the blue quinone alkali or colorless methanol false base structure transforms to light yellow chalcone structure. A similar conclusion can be obtained from the analysis of $a^{*}$ and $b^{*}$ values. The $C^{*}$ value reflects the singularity of each pigment structure in the solution. The more complex the pigment structure is, the lower the value of $C^{*}$ is. Based on the data in Table 3, the $C^{*}$ value is higher under strong acid $(\mathrm{pH}<3.0)$ or strong base $(\mathrm{pH}>11.0)$, which suggests the chemical structures of pigments in these two solutions are simple. They are mainly in the form of anthocyanin molten salt at $\mathrm{pH}<3.0$ and chalcone structure at $\mathrm{pH}>11.0$, which is consistent with the previous analysis. 
TABLE 9: Fastness properties of dyed silk fabrics with L. platyphylla fruit extracts.

\begin{tabular}{|c|c|c|c|c|c|c|c|}
\hline \multirow{2}{*}{ Dyeing methods } & \multirow{2}{*}{$\mathrm{pH}$ value of dyeing liquor } & \multirow{2}{*}{$\mathrm{WF}^{\mathrm{a}}$} & \multicolumn{2}{|c|}{ Perspiration } & \multirow{2}{*}{ Crock $_{\text {dry }}$} & \multirow{2}{*}{ Crock $_{\text {wet }}$} & \multirow{2}{*}{$\mathrm{LF}^{\mathrm{c}}$} \\
\hline & & & $\mathrm{CC}^{\mathrm{b}}$ & Staining & & & \\
\hline \multirow{7}{*}{ Control (without mordant) } & 1.0 & 2 & 2 & 1.5 & 2.5 & 2 & 1.5 \\
\hline & 3.0 & 2.5 & 2 & 1.5 & 2.5 & 2 & 1.5 \\
\hline & 5.0 & 2.5 & 2 & 1.5 & 2.5 & 2.5 & 1.5 \\
\hline & 7.0 & 2.5 & 2 & 1.5 & 2.5 & 2.5 & 1.5 \\
\hline & 9.0 & 2 & 2 & 2 & 2.5 & 2.5 & 1.5 \\
\hline & 11.0 & 2.5 & 2.5 & 2 & 2.5 & 2.5 & 1.5 \\
\hline & 13.0 & 2.5 & 2.5 & 2 & 2.5 & 2.5 & 2 \\
\hline \multirow{7}{*}{ Premordanting } & 1.0 & 3.5 & 3 & 3.5 & 3.5 & 3.5 & 2.5 \\
\hline & 3.0 & 3.5 & 3 & 3.5 & 3.5 & 3.5 & 4 \\
\hline & 5.0 & 4 & 3.5 & 4 & 4 & 4 & 3.5 \\
\hline & 7.0 & 4 & 3.5 & 3.5 & 4 & 3.5 & 3.5 \\
\hline & 9.0 & 3.5 & 3.5 & 3.5 & 4 & 3.5 & 3.5 \\
\hline & 11.0 & 4 & 3.5 & 3.5 & 4.5 & 3.5 & 3.5 \\
\hline & 13.0 & 4.5 & 3.5 & 4 & 4.5 & 3.5 & 3.5 \\
\hline \multirow{7}{*}{ Metamordanting } & 1.0 & 3.5 & 3 & 3 & 3.5 & 3.5 & 3.5 \\
\hline & 3.0 & 3.5 & 3.5 & 3.5 & 3.5 & 3.5 & 3.5 \\
\hline & 5.0 & 4 & 3.5 & 3.5 & 3.5 & 4 & 4 \\
\hline & 7.0 & 4 & 4 & 3.5 & 3.5 & 3.5 & 3.5 \\
\hline & 9.0 & 3.5 & 3.5 & 4 & 3.5 & 3.5 & 4 \\
\hline & 11.0 & 4 & 3.5 & 3.5 & 4 & 3.5 & 4 \\
\hline & 13.0 & 4 & 3.5 & 4 & 4 & 3.5 & 3.5 \\
\hline \multirow{7}{*}{ Postmordanting } & 1.0 & 3.5 & 3.5 & 3.5 & 3.5 & 3.5 & 3.5 \\
\hline & 3.0 & 3.5 & 3.5 & 3.5 & 3.5 & 3.5 & 4 \\
\hline & 5.0 & 4 & 3.5 & 3.5 & 4 & 4 & 4 \\
\hline & 7.0 & 4 & 4 & 3.5 & 4 & 3.5 & 4 \\
\hline & 9.0 & 4 & 3.5 & 3.5 & 4 & 3.5 & 3.5 \\
\hline & 11.0 & 4 & 4 & 4 & 4 & 3.5 & 3.5 \\
\hline & 13.0 & 4 & 4 & 4 & 4 & 3.5 & 3.5 \\
\hline
\end{tabular}

${ }^{\mathrm{a}}$ Washing fastness, ${ }^{\mathrm{b}}$ color change, and ${ }^{\mathrm{c}}$ light fastness.

3.4. Metal and Anthocyanin Chelation. Metals have been commonly used to stabilize the color of cyanidin, delphinidin, and petunidin, which have more than one free hydroxyl group in the chromane ring and are capable of metal chelation $[36,37]$. The most common metals in anthocyanin complexes are tin $(\mathrm{Sn})$, copper $(\mathrm{Cu})$, iron $(\mathrm{Fe})$, aluminum $(\mathrm{Al})$, and magnesium $(\mathrm{Mg})$ [38]. The main characteristic of anthocyanins and anthocyanindins with $o$-di-hydroxyl groups in the $\mathrm{B}$ ring $(\mathrm{Cy}, \mathrm{Dp}$, and $\mathrm{Pt}$ ) is their ability to form metal-anthocyanin complexes [35, 39]. The resultant formations of metal-anthocyanin complexes were suggested by the sample colors as shown by $L^{*}, a^{*}, b^{*}, C^{*}$, and $h$. Visible spectra of Sn chelated L. platyphylla fruits extracts at $\mathrm{pH} 1.0$ are shown in Figure 6. The color coordinates are shown in Table 4. As shown in Figure 6, with the increasing of the concentrations of $\mathrm{Sn}^{2+}$, the bathochromic maximum absorption wavelength of the L. platyphylla fruits shifts with $\Delta \lambda=5-8 \mathrm{~nm}$, the absorbance increases significantly, and the hyperchromic change is obvious.

Based on the CIELAB color system in Table 4, with the increasing of the $\mathrm{Sn}^{2+}$ concentration, the color indicators such as $L^{*}, a^{*}, b^{*}$, and $C^{*}$ of the solution show a decreasing trend. The color of the solution changes from red to blue violet as shown in Table 4, which suggests that the $\mathrm{Sn}^{2+}$ forms a violet complex with the red flavylium cation.

3.5. Dyeing of Silk by the Extracts. The silk was dyed using the L. platyphylla fruit extracts without mordanting, with tin premordanting, metamordanting or postmordanting at different $\mathrm{pH}$ values. The corresponding CIELAB values of dyed silk are shown in Tables 5, 6, 7, and 8, respectively. Some colour samples are shown in Figure 7. As concluded from the pigment color indicators, the dyed silk fabric without mordant dyeing shows different color results under different $\mathrm{pH}$ conditions, such as purple, blue, green, and yellow. The dyed color is light and the dyeing rate is low. The color is comparable deep with $\mathrm{pH}=1.0$ and becomes lighter with the increasing of the $\mathrm{pH}$ values.

Compared to silk fabrics dyed without mordanting in Table 5, silk fabrics dyed with stannous chloride mordant has deeper dyed color as shown in Table 6 to Table 8. The total color difference $\Delta E^{*}$ is increased obviously. The color of the fabric dyed with mordants appears to be red-purple, bluepurple, blue, green, yellow, and so forth.

Different $\mathrm{pH}$ values of dyeing solutions cause differences not only in hue color and $\Delta E^{*}$ values but also in $L^{*}, a^{*}, b^{*}$, 
$C^{*}$, and $h^{*}$ values. In case of mordant dyeing, the color depth of dyed silk fabric with stannous chloride postmordanting is low and the dyeing results are not satisfactory. When the dyed fabric is under postmordant processing, part of the anthocyanins transfers from fabric to the dyeing bath.

The washing fastness, perspiration fastness, crocking fastness, and light fastness were investigated with the results shown in Table 9. The results are satisfactory for $\mathrm{SnCl}_{2}$ mordanted fabrics due to the special chelation of anthocyanin color moieties and stannous.

\section{Conclusion}

The anthocyanin extracted from $L$. platyphylla fruits as a source of natural dyes has been utilized for the first time for silk fabrics dyeing to my best knowledge. In principal components analysis, nine anthocyanins from the fruits were identified by analyzing the results of the HPLC/DAD, MS, and MS/MS spectra. The five major anthocyanins related to delphinidin, petunidin, and malvidin derivatives take up $91.72 \%$ of total anthocyanin contents. In terms of acids used for extraction, 5\% citric acid gave better yield and deeper color compared with $0.1 \% \mathrm{HCl}$ and $0.5 \%$ TFA. In silk fabrics dyeing, the fruit pigment under mordant free condition presents different color results, changing between purple, blue, green, and yellow. However, from the point of the dyed color, the color is light and the dyed rate is low. The metal mordant such as tin in chelation with the extracts greatly enhances the dye depth and improves the fastness properties of the dyed silk fabrics, especially for silk fabrics dyed with premordanting and metamordanting.

\section{Conflict of Interests}

The authors have declared that they have no conflict of interests.

\section{References}

[1] T. Bechtold, A. Turcanu, E. Ganglberger, and S. Geissler, "Natural dyes in modern textile dyehouses-how to combine experiences of two centuries to meet the demands of the future?" Journal of Cleaner Production, vol. 11, no. 5, pp. 499509, 2003.

[2] L. G. Angelini, A. Bertoli, S. Rolandelli, and L. Pistelli, "Agronomic potential of Reseda luteola $\mathrm{L}$. as new crop for natural dyes in textiles production," Industrial Crops and Products, vol. 17, no. 3, pp. 199-207, 2003.

[3] E. Tsatsaroni, M. Liakopoulou-Kyriakides, and I. Eleftheriadis, "Comparative study of dyeing properties of two yellow natural pigments-effect of enzymes and proteins," Dyes and Pigments, vol. 37, no. 4, pp. 307-315, 1998.

[4] R. L. Jackman, R. Y. Yada, M. A. Tung, and R. A. Speers, "Anthocyanins as food colorants-a review," Journal of Food Biochemistry, vol. 11, no. 3, pp. 201-247, 1987.

[5] Ø. M. Andersen and M. Jordheim, "Anthocyanins," in Encyclopedia of Life Sciences (ELS), John Wiley \& Sons, Chichester, UK, 2010.
[6] Q. Du, G. Jerz, and P. Winterhalter, "Isolation of two anthocyanin sambubiosides from bilberry (Vaccinium myrtillus) by high-speed counter-current chromatography," Journal of Chromatography A, vol. 1045, no. 1-2, pp. 59-63, 2004.

[7] A. Kirca, M. Özkan, and B. Cemeroğlu, "Storage stability of strawberry jam color enhanced with black carrot juice concentrate," Journal of Food Processing and Preservation, vol. 31, no. 5, pp. 531-545, 2007.

[8] Q. Tian, R. M. Aziz, G. D. Stoner, and S. J. Schwartz, "Anthocyanin determination in black raspberry (Rubus occidentalis) and biological specimens using liquid chromatographyelectrospray ionization tandem mass spectrometry," Journal of Food Science, vol. 70, no. 1, pp. C43-C47, 2005.

[9] X. Wang, H. Tong, F. Chen, and J. D. Gangemi, "Chemical characterization and antioxidant evaluation of muscadine grape pomace extract," Food Chemistry, vol. 123, no. 4, pp. 1156-1162, 2010.

[10] P. Murapa, J. Dai, M. Chung, R. J. Mumper, and J. D’Orazio, "Anthocyanin-rich fractions of blackberry extracts reduce UVinduced free radicals and oxidative damage in keratinocytes," Phytotherapy Research, vol. 26, no. 1, pp. 106-112, 2012.

[11] D. Ghosh, "Anthocyanins and anthocyanin-rich extracts in biology and medicine: biochemical, cellular, and medicinal properties," Current Topics in Nutraceutical Research, vol. 3, no. 2, pp. 113-124, 2005.

[12] J. Kong, L. Chia, N. Goh, T. Chia, and R. Brouillard, "Analysis and biological activities of anthocyanins," Phytochemistry, vol. 64, no. 5, pp. 923-933, 2003.

[13] M. A. Lila, "Anthocyanins and human health: an in vitro investigative approach," Journal of Biomedicine and Biotechnology, vol. 2004, no. 5, pp. 306-313, 2004.

[14] T. K. McGhie and M. C. Walton, "The bioavailability and absorption of anthocyanins: Towards a better understanding," Molecular Nutrition and Food Research, vol. 51, no. 6, pp. 702713, 2007.

[15] S. B. Choi, J. D. Wha, and S. Park, "The insulin sensitizing effect of homoisoflavone-enriched fraction in Liriope platyphylla Wang et Tang via PI 3-kinase pathway," Life Sciences, vol. 75, no. 22, pp. 2653-2664, 2004.

[16] S. Hong, H. Jeong, H. Chung et al., "An herbal formula, Herbkines, enhances cytokines production from immune cells," Journal of Ethnopharmacology, vol. 98, no. 1-2, pp. 149-155, 2005.

[17] M. H. Kwak, J. E. Kim, I. S. Hwang et al., "Quantitative evaluation of therapeutic effect of Liriope platyphylla on phthalic anhydride-induced atopic dermatitis in IL-4/Luc/CNS-1 Tg mice," Journal of Ethnopharmacology, vol. 148, no. 3, pp. 880889,2013

[18] G. Li, W. Ra, J. Park et al., "Developing EST-SSR markers to study molecular diversity in Liriope and Ophiopogon," Biochemical Systematics and Ecology, vol. 39, no. 4-6, pp. 241-252, 2011.

[19] Y.-C. Tsai, S.-Y. Chiang, M. El-Shazly et al., "The oestrogenic and anti-platelet activities of dihydrobenzofuroisocoumarins and homoisoflavonoids from Liriope platyphylla roots," Food Chemistry, vol. 140, no. 1-2, pp. 305-314, 2013.

[20] Y. S. Oh, J. H. Lee, S. H. Yoon et al., "Characterization and quantification of anthocyanins in grape juices obtained from the grapes cultivated in Korea by HPLC/DAD, HPLC/MS, and HPLC/MS/MS," Journal of Food Science, vol. 73, no. 5, pp. 378389, 2008.

[21] J. C. Mi, L. R. Howard, R. L. Prior, and J. R. Clark, "Flavonoid glycosides and antioxidant capacity of various blackberry, 
blueberry and red grape genotypes determined by highperformance liquid chromatography/mass spectrometry," Journal of the Science of Food and Agriculture, vol. 84, no. 13, pp. 1771-1782, 2004.

[22] M. Fanzone, F. Zamora, V. Jofré, M. Assof, C. Gómez-Cordovés, and Á. Peña-Neira, "Phenolic characterisation of red wines from different grape varieties cultivated in Mendoza province (Argentina)," Journal of the Science of Food and Agriculture, vol. 92, no. 3, pp. 704-718, 2012.

[23] E. Alexandra Pazmio-Durán, M. M. Giusti, R. E. Wrolstad, and M. B. Glória, "Anthocyanins from banana bracts (Musa X paradisiaca) as potential food colorants," Food Chemistry, vol. 73, no. 3, pp. 327-332, 2001.

[24] L. Cabrita and Ø. M. Andersen, "Anthocyanins in blue berries of Vaccinium padifolium," Phytochemistry, vol. 52, no. 8, pp. 16931696, 1999.

[25] W. Huang, S. Zhang, G. Qin, W. Le, and J. Wu, "Isolation and determination of major anthocyanin pigments in the pericarp of $P$. Communis L. cv. 'Red Du Comices' and their association with antioxidant activity," African Journal of Agricultural Research, vol. 7, pp. 3772-3780, 2012.

[26] Y. Lu, L. Y. Foo, and H. Wong, "Isolation of the first C-2 addition products of anthocyanins," Tetrahedron Letters, vol. 43, no. 37, pp. 6621-6624, 2002.

[27] E. Sariburun, S. Şahin, C. Demir, C. Türkben, and V. Uylaşer, "Phenolic content and antioxidant activity of raspberry and blackberry cultivars," Journal of Food Science, vol. 75, no. 4, pp. C328-C335, 2010.

[28] C. Qin, Y. Li, W. Niu, Y. Ding, X. Shang, and C. Xu, "Composition analysis and structural identification of anthocyanins in fruit of waxberry," Czech Journal of Food Sciences, vol. 29, no. 2, pp. 171-180, 2011.

[29] M. Dueñas, J. J. Pérez-Alonso, C. Santos-Buelga, and T. Escribano-Bailón, "Anthocyanin composition in fig (Ficus carica L.)," Journal of Food Composition and Analysis, vol. 21, no. 2, pp. 107-115, 2008.

[30] M. T. Escribano-Bailón, C. Alcalde-Eon, O. Muñoz, J. C. Rivas-Gonzalo, and C. Santos-Buelga, "Anthocyanins in berries of Maqui (Aristotelia chilensis (Mol.) Stuntz)," Phytochemical Analysis, vol. 17, no. 1, pp. 8-14, 2006.

[31] M. P. Kähkönen, J. Heinämäki, V. Ollilainen, and M. Heinonen, "Berry anthocyanins: isolation, identification and antioxidant activities," Journal of the Science of Food and Agriculture, vol. 83, no. 14, pp. 1403-1411, 2003.

[32] T. Sukwattanasinit, J. Burana-Osot, and U. Sotanaphun, "Spectrophotometric method for quantitative determination of total anthocyanins and quality characteristics of Roselle (Hibiscus sabdariffa)," Planta Medica, vol. 73, no. 14, pp. 1517-1522, 2007.

[33] J. Lee, R. W. Durst, and R. E. Wrolstad, "Determination of total monomeric anthocyanin pigment content of fruit juices, beverages, natural colorants, and wines by the $\mathrm{pH}$ differential method: collaborative study," Journal of AOAC International, vol. 88, no. 5, pp. 1269-1278, 2005.

[34] J. H. Lee and M. Choung, "Identification and characterisation of anthocyanins in the antioxidant activity-containing fraction of Liriope platyphylla fruits," Food Chemistry, vol. 127, no. 4, pp. 1686-1693, 2011.

[35] A. Castañeda-Ovando, M. de Lourdes Pacheco-Hernández, M. Elena Páez-Hernández, J. A. Rodríguez, and C. A. Galán-Vidal, "Chemical studies of anthocyanins: a review," Food Chemistry, vol. 113, pp. 859-871, 2009.
[36] T. Goto, H. Tamura, T. Kawai, T. Hoshino, N. Harada, and T. Kondo, "Chemistry of metalloanthocyanins," Annals of the New York Academy of Sciences, vol. 471, pp. 155-173, 1986.

[37] Y. Osawa, "Copigmentation of anthocyanins," in Anthocyanins as Food Colors, P. Markakis, Ed., pp. 41-68, Academic Press, New York, NY, USA, 1982.

[38] R. N. Cavalcanti, D. T. Santos, and M. A. A. Meireles, "Nonthermal stabilization mechanisms of anthocyanins in model and food systems-an overview," Food Research International, vol. 44, no. 2, pp. 499-509, 2011.

[39] G. A. Ellestad, "Structure and chiroptical properties of supramolecular flower pigments," Chirality, vol. 18, no. 2, pp. 134-144, 2006. 

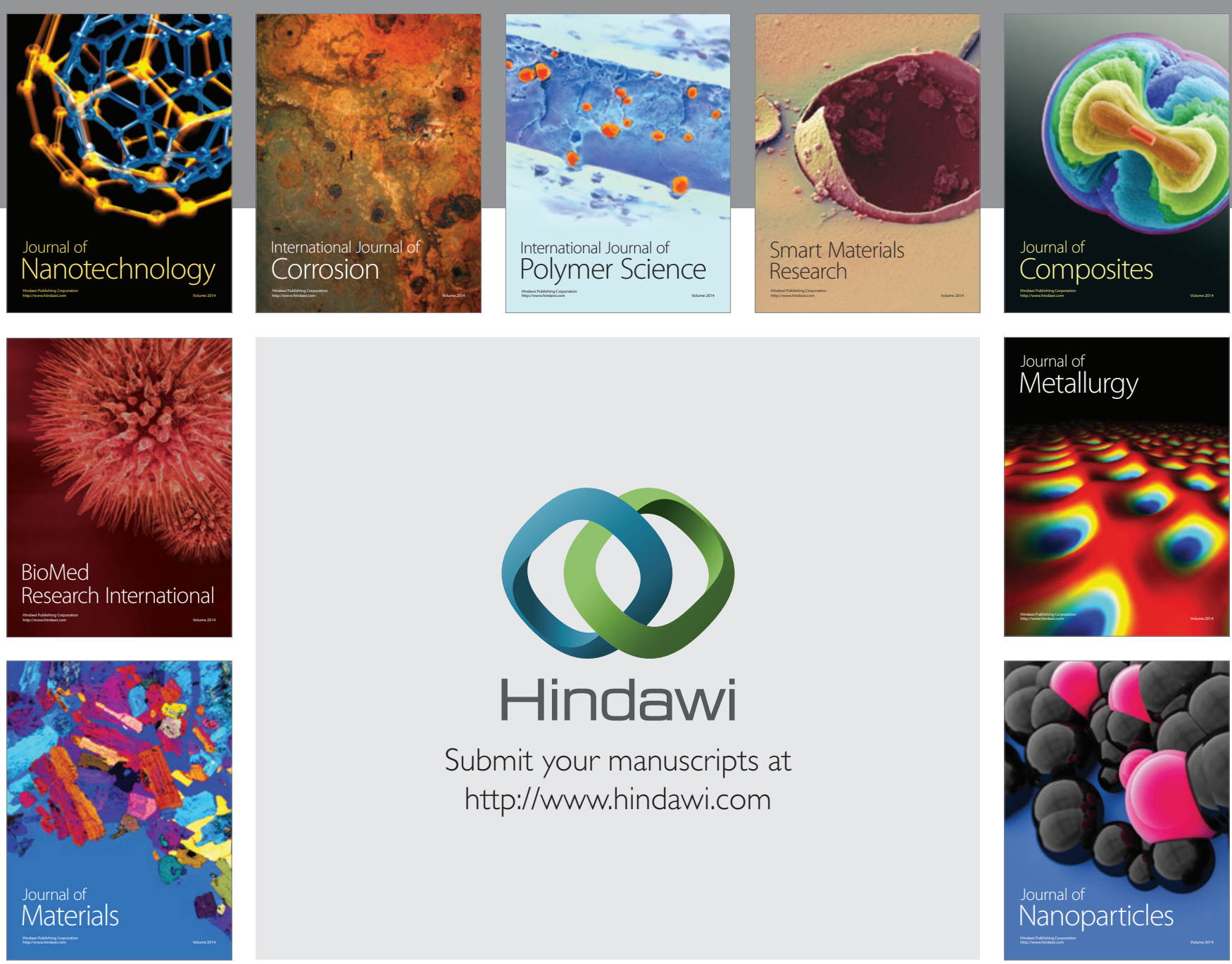

Submit your manuscripts at http://www.hindawi.com
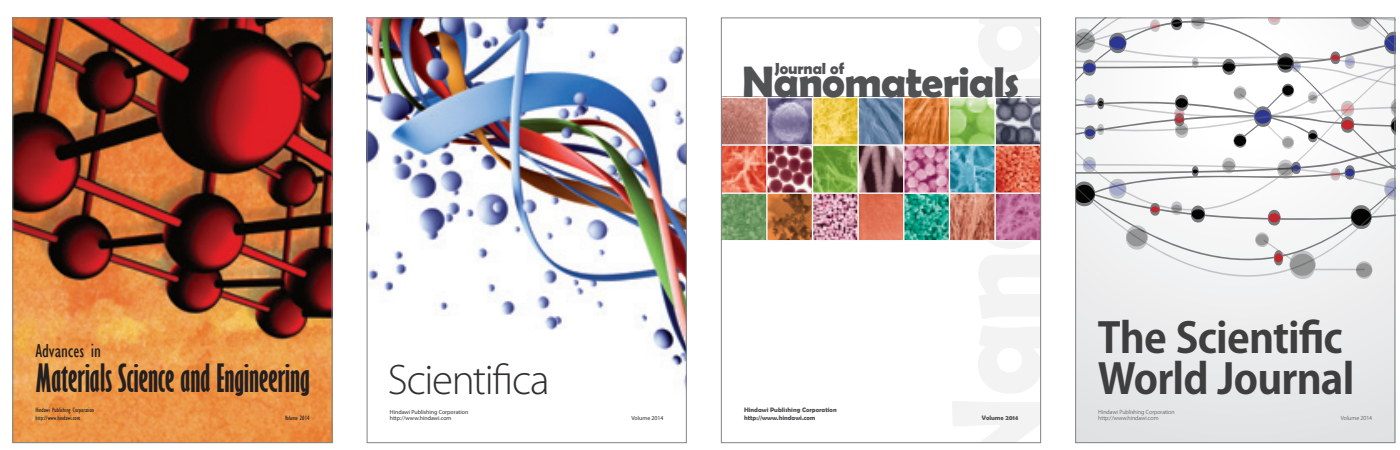

\section{The Scientific World Journal}
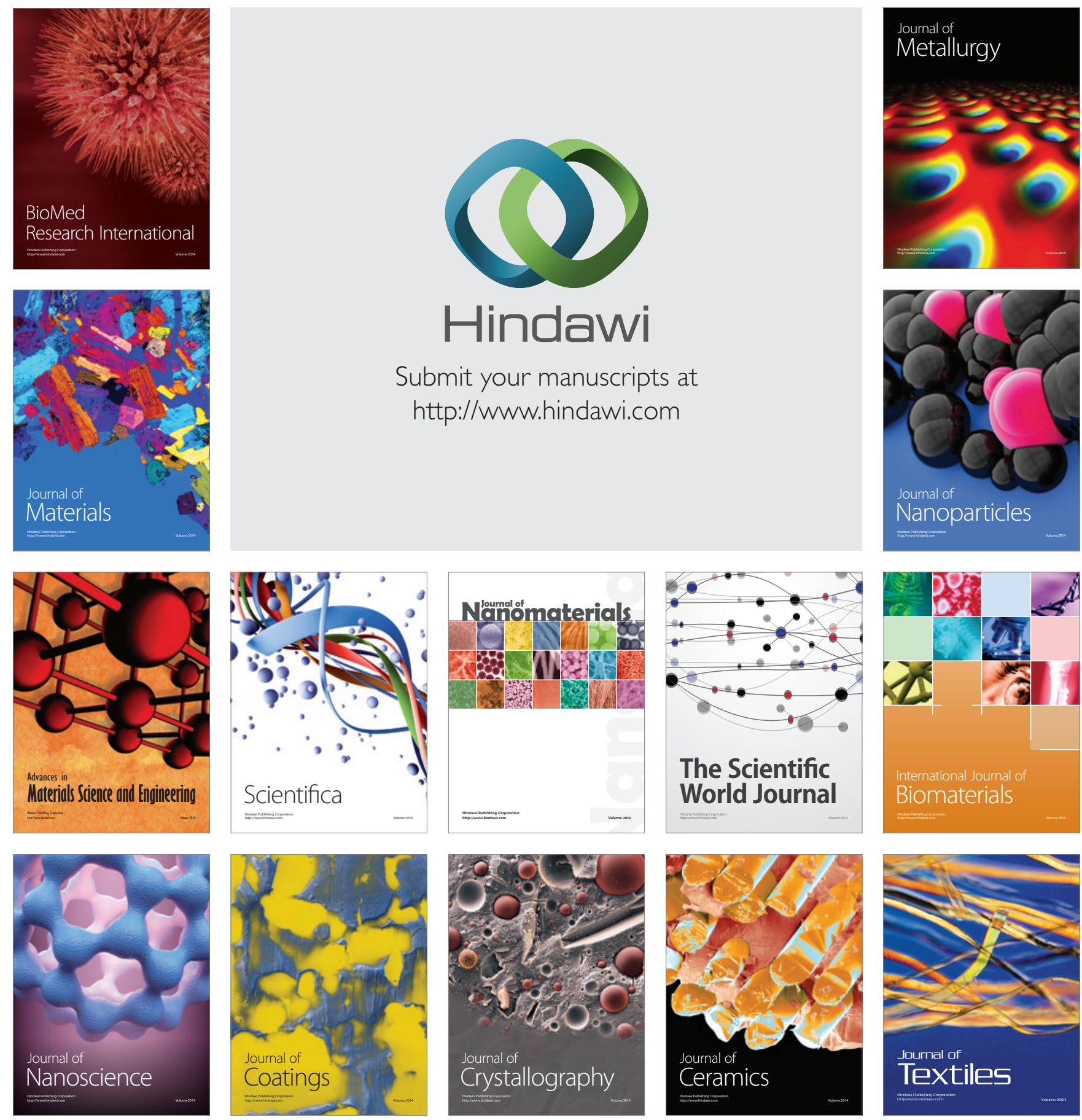